\title{
Meeting report \\ Workshop on The Epidemiology of the ATM Gene: Impact on Breast Cancer Risk and Treatment, Present Status and Future Focus, Lillehammer, Norway, 29 June 2002
}

\author{
Jonine L Bernstein ${ }^{1}$, Daniela Seminara² and Anne-Lise Børresen-Dale ${ }^{3}$
}

1Department of Community Medicine, Mount Sinai School of Medicine, New York, USA

${ }^{2}$ Division of Cancer Control and Population Sciences, National Cancer Institute, Bethesda, Maryland, USA

3Institute for Cancer Research, The University Hospital \& The Norwegian Radium Hospital, Montebello, Oslo, Norway

Correspondence: Anne-Lise Børresen-Dale, PhD, Institute for Cancer Research, The University Hospital \& The Norwegian Radium Hospital, Montebello, 0310, Oslo, Norway. Tel: +47 22934419; fax: +47 22934440; e-mail: alb@radium.uio.no

Received: 25 September 2002

Accepted: 2 October 2002

Published: 9 October 2002
Breast Cancer Res 2002, 4:249-252 (DOI 10.1186/bcr551)

(C) 2002 BioMed Central Ltd

(Print ISSN 1465-5411; Online ISSN 1465-542X)

\begin{abstract}
The role of ataxia-telangiectasia mutated (ATM) heterozygosity in cancer is uncertain. In vitro studies of cells from ATM heterozygotes provide strong evidence of radiation sensitivity. Some, but not all, clinical studies suggest an increased risk of breast cancer among ATM gene carriers, and this risk may be greater among those exposed to radiation. This possible excess risk of breast cancer associated with ATM heterozygosity constitutes the basis for several genetic epidemiological studies designed to clarify the role that the ATM gene plays in the etiology of breast and other cancers. The primary focus of this international, multidisciplinary, National Cancer Institute-sponsored workshop was to discuss ongoing and planned epidemiologic studies aimed at understanding the complexities of the ATM gene and its role in carcinogenesis. The invited participants were from diverse disciplines including molecular and clinical genetics, radiation biology and physics, epidemiology, biostatistics, pathology, and medicine. In the present meeting report, the aims of each project are described.
\end{abstract}

Keywords: ATM gene, breast cancer risk, heterozygote, radiation

\section{Introduction}

The genetic disease ataxia-telangiectasia $(A-T)$ is characterized by hypersensitivity to ionizing radiation, by genomic instability, and by predisposition to cancer, especially breast cancer. Early reports estimated that $3.8 \%$ of breast cancer cases could be attributed to ataxia-telangiectasia mutated (ATM) heterozygosity, with a possible range of $1-13 \%$. If, as some evidence suggests, missense mutations may be responsible for the majority of breast cancer among ATM heterozygotes [1], then these often cited figures underestimate the actual prevalence of the gene since they were derived from studies of A-T patients where the prevalence of truncating mutations is high and the prevalence of missense mutations is low. Furthermore, although inconsistent, some studies suggest that the ATM gene may be associated with an increased risk of breast cancer as high as 15-fold [2-12].

This possible excess risk of breast cancer associated with ATM heterozygosity, and the known biochemical interactions between the protein products of the ATM and $B R C A 1$ genes, are the basis for several genetic epidemiologic studies designed to reconcile these conflicting results and to clarify the role that the ATM gene plays in the etiology of breast cancer and other cancers. The international, multidisciplinary, National Cancer Institute-sponsored workshop was organized as a forum for discussion of these ongoing and planned epidemiological studies. The 45 invited participants are key collaborators on these studies, with expertise including molecular and clinical 
genetics, radiation biology and physics, epidemiology, biostatistics, pathology, and medicine. The following is a summary of projects presented.

\section{The Women's Environmental, Cancer, and Radiation Epidemiology study}

JL Bernstein (Mount Sinai School of Medicine, New York, USA) presented an overview of the Women's Environmental, Cancer, and Radiation Epidemiology (WECARE) study ( $\mathrm{NCl}-\mathrm{CA83178}$; for study investigators, see Appendix). The WECARE study (http://146.203.34.23/atmstudy/front.html) is an international, multicenter, population-based, genetic epidemiological study designed to test the hypothesis that the incidence of contralateral breast cancer is increased among women who are heterozygous for ATM and who received radiation therapy as treatment for their first primary breast cancer. The 700 'cases' are women with bilateral breast cancer, and the 1400 individually counter-matched 'controls' are women with unilateral breast cancer being identified and interviewed through population-based tumor registries in the United States and in Denmark.

The full spectrum of ATM mutations is examined using an efficient staged approach (denaturing high-performance liquid chromatography followed by sequencing), which has been standardized in all four laboratories performing the analyses. Lifetime exposure to radiation, including the radiation therapy scatter dose to the contralateral breast, is also assessed. The study's premise is that any important genetic factors (e.g. ATM gene mutations) and etiological factors for breast cancer (e.g. radiation exposure) will be more prevalent among women who already have a first primary cancer than they would be among women in the general population. The WECARE study thus presents a promising context for sorting out complex gene-environment interactions involved in breast carcinogenesis.

\section{Breast cancer incidence among A-T family members}

The overall objective of this study, as presented by $\mathrm{R}$ Haile (University of Southern California, Los Angeles, CA, USA; for study investigators see Appendix), is to determine whether subjects who are ATM heterozygotes have a higher than expected risk of cancer, with a primary focus on breast cancer. Collaborators in Argentina, Bulgaria, Canada, Costa Rica, Germany, Israel, Italy, Turkey, and the United States who have already identified A-T families are collecting and verifying the reported history of cancer in parents and grandparents of A-T cases. In addition, genetic testing for mutations in the ATM gene in these families will be conducted. Participating centers have at present collectively identified 461 A-T families. Also planned are exploratory analyses addressing the issue of the heterogeneity of risk between subgroups defined by country of origin and specific type of mutation. It is under- be necessary to address questions of heterogeneity in an informative manner.

\section{ATM variants and breast cancer risk among women at high risk for breast cancer}

$G$ Chenevix-Trench (Queensland Institute of Medical Research, Brisbane, Australia; for study investigators see Appendix) discussed studies of A-T families that suggest female obligate heterozygotes have an increased risk of breast cancer. Yet neither linkage analyses or mutation studies have provided supporting evidence for these studies.

Two recurrent mutations, $7271 \mathrm{~T}>\mathrm{G}$ and IVS10-6T $>\mathrm{G}$, conferring an elevated risk were recently reported. These mutations were examined in a population-based, casecontrol series of breast cancer patients as well as in multiple-case breast cancer families. They found three multiplecase families in which one or other of these mutations segregated with breast cancer. The estimated average penetrance of these mutations was 60\% (95\% confidence interval, 32-90\%) up to age 70 years, equivalent to a 16 -fold (95\% confidence interval, 6-38) increased risk. Functional analyses in heterozygous cell lines indicated that both mutations act in a dominant-negative manner.

The conclusion was that certain ATM gene mutations, missense and truncating, are associated with a sufficiently high risk of breast cancer and that they can be found in multiple-case breast cancer families. These families also contained multiple cases of colorectal and gastric cancer, raising the possibility that these mutations also confer high risks for these cancer types.

Full mutation analysis of the ATM gene is now underway in a large panel of non-BRCA1/BRCA2 breast cancer families, as are kinase assays of lymphoblastoid cell lines from these families as a screen for dominant-negative mutations.

\section{Radiation exposure, ATM gene mutations and breast cancer risk}

The extent to which ATM heterozygosity increases the risk of radiation-induced breast cancer is currently being explored, as presented by A Broeks (The Netherlands Cancer Institute, Amsterdam, The Netherlands; for study investigators see Appendix).

Three case-control studies were conducted, with cases defined as patients who developed breast cancer following therapeutic or diagnostic radiation before age 50 years. Study 1 consisted of 58 patients with contralateral breast cancer following therapeutic radiation for their first breast cancer. Study 2 included 40 patients with breast cancer following mantle-field irradiation for Hodgkin's disease. Finally, study 3 involved 30 patients who developed breast cancer after diagnostic mammographic screening following a diagnosis of benign breast disease. For each case, four 
age-matched controls were selected who received radiation exposure for the same disease or diagnostic procedure but who did not develop breast cancer.

The proportions of ATM heterozygotes were determined using the denaturing gradient gel electrophoresis mutation detection method. In study 1 , a substantial number of ATM protein truncating mutations and a variety of missense mutations were detected, both among the cases and the control individuals. In a case-control setting, taking all risk factors into account, the results of these three studies were analyzed. It appears that ATM heterozygotes may have an increased risk (relative risk, 3.1) of developing a specific type of breast cancer, characterized by frequent bilateral occurrence, by early age at onset, and by longterm survival.

\section{Role of the ATM gene in breast tumor development and radiation sensitivity}

The expression of the ATM and p53 proteins has been studied in breast in situ carcinomas and in invasive carcinomas. The results presented by J Hall (International Agency for Research on Cancer, Lyon, France; for study investigators see Appendix) indicate that, in most of the sporadic breast carcinomas, the DNA damage response as well as also other signaling pathways activated by the ATM and p53 multifunctional proteins [13] were compromised. Consistent with this, ATM expression was dramatically reduced in approximately $30 \%$ of sporadic breast neoplasms [14]. The expression profiles of these and other proteins implicated in DNA double-strand break repair (BRCA1, NBS1, MRE11 and Rad50) are presently being assessed in breast tumors.

Additionally, molecular characterization of lymphoblastoid cell lines established from radiosensitive and nonradiosensitive patients is being used to investigate the role of alterations in the ATM gene as a risk factor in breast cancer development. In some cell lines, the level of cell survival and p53 induction after ionizing radiation exposure is lower than that observed in control cell lines, indicating an alteration in the ATM signaling pathway. Using the protein truncating tests and restriction endonuclease fingerprinting techniques, a variety of rare ATM sequence alterations and polymorphisms have been detected in cases. The frequency of these alterations and polymorphisms in control samples is under investigation to establish whether their presence is associated with either radiation sensitivity or increased breast cancer risk.

\section{Conclusions}

The primary purpose of this meeting was to bring together scientists from diverse disciplines who are currently engaged in research aimed at understanding the complexities of the ATM gene and its role in breast carcinogenesis. The encouraging preliminary results presented, coupled with the long-term opportunities afforded from these studies and the recent advances in genomics and molecular genetics technology, set the stage for reconciling the conflicting results of prior genetic and epidemiologic studies. It is the scientists' joint goal that these studies contribute to our understanding, in order to correctly assess the population frequency of various types of ATM mutations, to determine the correlation between ATM genotype and the breast (or other) cancer phenotype, to clarify the function of the A-T gene product within the radiation damage repair pathways and, importantly, to precisely identify major genetic and environmental effect modifiers. In turn, this information will allow direct evaluation of the proportion of breast cancer directly related to mutations in the ATM gene (population attributable risk), and will facilitate the design of appropriate preventive and therapeutic strategies targeted to a population at increased risk for developing breast cancer.

\section{Acknowledgements}

This workshop received funding from the National Cancer Institute, Bethesda, MD, USA. Financial support to Janet Hall (International Agency for Research on Cancer, Lyon, France) from the Association pour la Recherche sur le Cancer, La Ligue Nationale Contre le Cancer (Comités Départemental du Rhône, Ardèche and Drôme) and EDF is gratefully acknowledged.

\section{References}

1. Gatti RA, Tward A, Concannon P: Cancer risk in ATM heterozygotes: a model of phenotypic and mechanistic differences between missense and truncating mutations. Mol Genet Metab 1999, 68:419-423.

2. Pippard E, Hall A, Barker D, Bridges B: Cancer in homozygotes and heterozygotes of ataxia-telangiectasia and xeroderma pigmentosum in Britain. Cancer Res 1988, 48:2929-2932.

3. Borresen A, Andersen T, Tretli S, Heilberg A, Moller P: Breast cancer and other cancers in Norwegian families with ataxiatelangiectasia. Genes Chromosomes Cancer 1990, 2:339-340.

4. Swift M, Morrell D, Massey R, Chase C: Incidence of cancer in 161 families affected by ataxia-telangiectasia. $N$ Engl J Med 1991, 325:1831-1836.

5. Easton D: Cancer risks in A-T heterozygotes. Int J Rad Biol 1994, 66:S177-S182.

6. Athma P, Rappaport R, Swift M: Molecular genotyping shows that ataxia-telangiectasia heterozygotes are predisposed to breast cancer. Cancer Genet Cytogenet 1996, 92:130-134.

7. Janin N, Andrieu N, Ossaian K, Lauge A, Croquette M, Griscelli C, Debre M, Bressac-de-Paillertes B, Aurias A, Stoppa-Lyonnet D: Breast cancer risk in ataxia telangiectasia (AT) heterozygotes: haplotype study in French AT families. $\mathrm{Br} J$ Cancer 1999, 80: 1042-1045.

8. Inskip H, Kinlen L, Taylor A, Woods C, Arlett C: Risk of breast cancer and other cancers in heterozygotes for ataxia telangiectasia. Br J Cancer 1999, 79:1304-1307.

9. Shafman TD, Levitz S, Nixon AJ, Gibans LA, Nichols KE, Bell DW, Ishioka C, Isselbacher KJ, Gelman R, Garber J, Harris JR, Haber DA: Prevalence of germline truncating mutations in ATM in women with a second breast cancer after radiation therapy for a contralateral tumor. Genes Chromosomes Cancer 2000, 27:124-129.

10. Teraoka SN, Malone KE, Doody DR, Suter NM, Ostrander EA Daling JR, Concannon P: Increased frequency of ATM mutations in breast carcinoma patients with early onset disease and positive family history. Cancer 2001, 92:479-487.

11. Olsen JH, Hahnemann JM, Borresen-Dale AL, Brondum-Nielsen $K$, Hammarstrom L, Kleinerman R, Kaariainen H, Lonnqvist T, Sankila R, Seersholm N, Tretli S, Yuen J, Boice JD Jr, Tucker M: Cancer in patients with ataxia-telangiectasia and in their relatives in the nordic countries. J Nat/ Cancer Inst 2001, 93:121-127. 
12. Chenevix-Trench G, Spurdle AB, Gatei M, Kelly H, Marsh A, Chen X, Donn K, Cummings M, Nyholt D, Jenkins MA, Scott C, Pupo GM, Dork T, Bendix R, Kirk J, Tucker K, McCredie MR, Hopper JL, Sambrook J, Mann GJ, Khanna KK: Dominant negative ATM mutations in breast cancer families. J Natl Cancer Inst 2002, 94:205-215.

13. Angele S, Treilleux I, Taniere P, Martel-Planche G, Vuillaume M, Bailly C, Bremond A, Montesano R, Hall J: Abnormal expression of the ATM and TP53 genes in sporadic breast carcinomas. Clin Cancer Res 2000, 6:3536-3544.

14. Kairouz R, Clarke RA, Marr PJ, Watters D, Lavin MF, Kearsley JH, Lee CS: ATM protein synthesis patterns in sporadic breast cancer. Mol Pathol 1999, 52:252-256.

\section{Appendix}

\section{WECARE Study Collaborative Group}

Principal Investigator

Jonine L Bernstein (Mount Sinai School of Medicine, New York, USA).

\section{Co-Principal Investigators}

W Douglas Thompson, Chair of the Epidemiology and Biostatistics Core (University of Southern Maine, Portland, ME, USA), Robert W Haile (University of Southern California, Los Angeles, CA, USA), Leslie Bernstein, Chair of the Data Collection Core (University of Southern California, Los Angeles, CA, USA), and Patrick J Concannon, Chair of the Laboratory Core (Virginia Mason Research Center, Seattle, WA, USA).

\section{Coordinating Centers}

Susan L Teitelbaum (Project Director), Gertrud S Berkowitz (Epidemiologist), Xiaolin Liang (Informatics Specialist), Monica Katyal (Project Coordinator), and Stephanie Skoler (Project Coordinator) (Mount Sinai School of Medicine, New York, USA); Daniela Seminara (Program Officer) (National Cancer Institute, Bethesda, MD, USA).

\section{Laboratories}

Sharon Teraoka (Laboratory Director) (Virginia Mason Research Center, Seattle, WA, USA); Anh T Diep (Laboratory Director), Nianmin Zhou (Laboratory Manager), and Yong Liu (Director of Blood Processing) (University of Southern California, Los Angeles, CA, USA); Anne-Lise Børresen-Dale (Laboratory Director), and Laila Jansen (Laboratory Manager) (Norwegian Radium Hospital, Oslo, Norway); Barry S Rosenstein (Laboratory Director), and David P Atencio (Laboratory Manager) (Mount Sinai School of Medicine, New York, USA); Richard A Gatti (Consultant) (University of California at Los Angeles, CA, USA).

\section{Data Collection Centers}

Laura Donnelly (Project Manager), and Maya MahueGiangreco (Project Manager) (University of Southern California, Los Angeles, CA, USA); Jørgen H Olsen (Director), and Lene Mellemkjær (Project Manager) (Danish Cancer Society, Copenhagen, Denmark); Kathleen E Malone
Hutchinson Cancer Research Center, Seattle, WA, USA); Hoda Anton-Culver (Director), and Joan Largent (Project Manager) (University of California at Irvine, Irvine, CA, USA); Charles F Lynch (Director), and Jeanne DeWall (Project Manager) (University of lowa, lowa City, IA, USA).

\section{Radiation Core}

Marilyn Stovall (Dosimetry Laboratory Director and Chair, Radiation Core) (University of Texas, MD Anderson Cancer Center, Houston, TX, USA); Roy E Shore (Epidemiologist) (New York University, New York, USA); John D Boice Jr (Consultant) (International Epidemiology Institute, Rockville, MD, and Vanderbilt University, Nashville, TN, USA).

\section{Epidemiology and Biostatistics Core}

Duncan C Thomas, and Bryan M Langholz (University of Southern California, Los Angeles, CA, USA).

\section{Breast cancer incidence among A-T family members study investigators}

Robert W Haile, Duncan C Thomas, and Leslie Bernstein (University of Southern California, Los Angeles, CA, USA); Richard A Gatti (University of California at Los Angeles, Los Angeles, CA, USA).

\section{ATM variants and breast cancer risk among women at high risk for breast cancer study investigators}

G Chenevix-Trench, D Nyholt, and KK Khanna (Queensland Institute of Medical Research, Brisbane, Australia); A Jenkins, and JL Hopper (The University of Melbourne, Centre for Genetic Epidemiology, Victoria, Australia); C Scott, and J Sambrook (Peter MacCallum Cancer Institute, Victoria, Australia); T Dörk (Medical School Hannover, Hannover, Germany).

\section{Radiation exposure, ATM gene mutations and} breast cancer risk study investigators

Annegien Broeks (Division of Experimental Therapy), Flora E van Leeuwen (Department of Epidemiology), and Laura J van't Veer (Department of Pathology) (The Netherlands Cancer Institute, Amsterdam, The Netherlands).

\section{Role of the ATM gene in breast tumor development and radiation sensitivity study investigators}

Janet Hall, Sandra Angèle, Michèle Vuillaume, and Philippe Tanière (International Agency for Research on Cancer, Lyon, France); Isabelle Treilleux, and Alain Brémond (Centre Régional Léon Bérard, Lyon, France); Jean-Pierre Gérard, and Pascale Romestaing (Service de Radiothérapie-Oncologie, Centre Hospitalier Lyon Sud, Pierre Bénite, France). 